\title{
Effect of Customer Relationship Management (CRM) on Marketing Performance, a Case Study in Mellat Bank of Khorram-abad County
}

\author{
Goudarzi M. ${ }^{1 *}$, Mossallami Aghili S. ${ }^{2}$, Mokhtary Tajeek Z. ${ }^{2}$ \\ ${ }^{1}$ Assistant Professor, Department of Management, University of Lorstan, Khorram Abad, \\ Iran \\ ${ }^{2}$ MSc. Student of Marketing Management, University of Lorstan, Khorram Abad, Iran
}

Corresponding Author E-mail: Amir.jnz@gmail.com

Received: 24 October 2018, Revised: 05 December 2018, Accepted: 20 December 2018

\begin{abstract}
Today with more competiveness of industries, markets, and working atmosphere in productive and service organizations, what is very important for maintaining clients present, for attracting new clients and as a result increasing growth of success in organizations is having a suitable relation with clients. Banks are among organizations which are not an exception. Nowadays, due to increasing rate of banks ' privatization, it can be argued that significance of attracting clients for banks is more than every time. This study tried to investigate the effect of CRM on marketing performance in banking industry. The research method was applied and survey and descriptive. The sample were 5 branches from Mellat Banks across Khoram-abad County and their clients. There are 45 personnel in this branch and according to Morgan Table, the sample size was 40 people. Clients 1 example was considered to gather information. One questionnaire was designed for bank organization and another one was prepared for banks`clients whose reliability and validity were approved. The results of the study indicates that CRM is ineffective on marketing performance.
\end{abstract}

Keywords: CRM, Marketing Performance, Knowledge Management.

\section{Introduction}

At the start of twenty first century, the world faced some significant changes in all aspects, especially competing in market, technological innovations and needs of clients (Jafarnejad and Shahaei, 2007). The changes caused application of various techniques in order to improve market performance of organizations. The success of each of the techniques can be reflected in performance of companies and company performance is success level of it in creating values for different sectors of market.

Today, presenting the best performance on marketing is the most fundamental concern of company managers; therefore, they try to achieve a top performance by 
exploiting various techniques, which have a wide usage are CRM.

The attitude of companies and institutions has to focus on more attraction of clients regarding expanding competitiveness space. Passing from traditional economy and with intensification of competitions, client has become the main element of all organizational activities; in a way that from competing aspect, survival and continuity of organizations depends on identifications and attraction of new clients and maintaining them (Elahi and Heydari, 2005).

Today's economic and business improvement of the country depends on banking system improvement and also banking industries of other developed countries like all the industries of the country. At the present time, a high level of ownership in this industry is in hand of governments. But with the appearance of private banks competition in this industry, there is has a long distance between the level of our banks and that of world banking. Gaining competitive priority needs better services. With discovery of the relationship of marketing performance and CRM different banks can find out their weakness points and as a result they will understand their clients' demands and try to meet them (Taherpour Kalantari and Tayebi Tolou, 2010).

The aim of the research is investigating the relationship of CRM with marketing performance in banking industry, wince marketing and its philosophy is discovering clients' needs and meeting them in the best possible way.

CRM is one of the techniques which was defined and developed in the 90`s along with expansion of information and communication technologies as a key approach in business with the objective of returning to private marketing. Generally, modification of clients' behavior in financial and service institutions especially in banks is more sensitive due to financial nature of its activities and needs an accurate and on-time planning by managers of banking systems. A client in a bank is regarded at least one asset. Today, banking system is bound to see itself in client's nature and to try to understand desire and willingness of its clients in the fully competitive atmosphere and must do their best to meet satisfaction of its clients. In today's marketing, the cost of losing a client equals to losing interests related to losing interests regarding related to services a client needs in their life and this is a warning for the bank. Moreover, service interests resulting from new clients will be lost, too. Therefore, clientorientation is a very sensitive element which we must care about a lot. To meet client satisfaction, we should consider some points whose most important ones is clear response to daily needs of clients, service diversity and new and innovative services (Venus and Safaeian, 2004).

\section{Definitions and Theories}

\section{-Customer Relationship Management}

CRM is the abbreviation of customer relationship management or systems of customer relationship management. In fact, the systems are strategies for gathering trading behaviors and needs of clients to create a strong relationship. Finally, a strong relationship with clients is the most important secret in success of every business (Berus and Ken, 2004).

Traditional strategies of marketing regarding forth definition are centralized in order to increase portion and their preliminary attention has been increasingly paid to transactions between seller and buyer. In this regard size of selling performance criterions was 
marketing strategies and tactics but CRM is a type of business strategy which passed beyond increase of transaction size and its aim is increasing profiting, income and client satisfaction. To achieve these objectives, organizations apply a wide set of tools, procedures, methods and communication with clients (Elahi and Heydari, 2005).

In marketing literature some correlated definitions are provided on CRM, some of which are considered to have a similar relationship with marketing (Berry, 1983).

There are different views on CRM some of which are presented in the research:

Kin Seed considers CRM as strategic usage of information, process, technologies and people for managing client relationship during life cycle of client. Kou et al, 2004 considers CRM as a unified strategy of client in an organization for more effective management of clients by providing materials and certain services and maximizing value of life period of client.
Kumar and Ramani define CRM as a process of achieving and keeping a constant relation with clients through suitable conduct with each one of clients based on their interest, instead of performing marketing programs. CRM is a notion which makes an organization capable in providing certain services for every client and as a result creating a friendly relationship with clients.

CRM may create a one-to-one experience which is noticed. Therefore, it makes new marketing opportunities based on past and clients' preference (Peppers, Rogers and Dorf, 1999).

\section{Objectives of CRM}

In Table 1, the objectives of CRM is investigated from different views. Generally, the aim of CRM is to gain a competitive advantage in managing client and eventually increasing profitability (Gartner Group, 2001).

Table 1. Goals of CRM from different views (Hadizadeh Moghaddam et al., 2010)

$\begin{array}{cc}\text { CRM goals with views of Burnett (2001) } & \begin{array}{c}\text { 1. Saving in costs of gathering clients information } \\ \text { 2. Income increase as a result of recognizing clients } \\ \text { 3. Strategic effects }\end{array} \\ \text { CRM goals with views of Swift (2001) } & \begin{array}{c}\text { 1. Improvement of communication process with real } \\ \text { clients }\end{array} \\ & \begin{array}{c}\text { 2. Presenting real products for each client } \\ \text { 3. Presenting real products through suitable } \\ \text { networks for each client }\end{array} \\ \text { 4. Presenting real products at the right time } \\ \text { 1. Customization }\end{array}$

\section{Dimensions and Elements of CRM}

Sin, Tse, Yim (2005) mentioned CRM elements which are as follows:

The first dimension focuses on key clients, including a wide focus on real clients and continuous submission of valued added to select key clients through privatized and desirable supplies.

The second dimension is CRM organization. CRM necessarily means 
fundamental changes in the approach of organizing and processes of companies' business (Hoffman and Kashmeri, 2000). Companies must care about real challenges of organization regarding starting CRM (Agarwal and Harding and Schumacher, 2004).

The third dimension is knowledge management. According to the view based on company knowledge, the main logic for existence of a company is creating, transferring and applying knowledge. From the view of CRM, knowledge can be defined the experience or applied study learnt by clients.

The fourth dimension is CRM based on technology. The data of client is vital for successful performance of CRM (Abbot and Stone and Buttle, 2001). As a result, technology plays a key role in CRM and in increasing level of intelligence (Boyle, 2004).

\section{Organizational performance}

This performance indicates how an organization reaches its goals and fulfils its mission. Organizational performance means start of a certain condition and reaching an accurate goal which may contain several points of objective such as market portion, selling size, motivation of employees, client satisfaction, level of quality and so on (Boisvert, 2006). This research aims at marketing performance and its elements are effectiveness, efficiency and adaptability.

Effectiveness: it measures level of achieving organizational objectives. In other words, service/product effects become quantitative and it specifies to what extent service/product presented are consistent with standards and goals of organization.

Effectiveness is a qualitative definition and shows level of client satisfaction with service/product provided.
Efficiency: It is factor ratio to data or in other words its ratio of material reduction or final services applied in resources in it. Efficiency is a qualitative definition and basically points out level client satisfaction or level of achieving the goals.

Adaption: it means the adaptation of organization to environmental changes and challenges.

The only research which is present on the effect of CRM on marketing performance was written by Taher Pour Kalantari and Tayebi Tolou in 2010 entitled" Relation of CRM with performance". In this research the relation of CRM to performance of private and state banks in Tehran was investigated. The result of the research indicated that the relationship between marketing performance and CRM in banking industry of Iran is low. In other words, the results of the research show that not only banks are not familiar with CRM technology, but also, they do not sufficiently care about CRM logic. Other research studies which were conducted at least on one of the variables are as follows:

In his research called" investigating quality of services of CRM and preparing optimum program of CRM in banking system using TOPSIS technique, "Amiry (2009) investigated this issue in Tejarat Bank of Shiraz. The main objective of conducting the research was preparing program of improving CRM in Tejarat Bank of Shiraz. To so doing, after determining factors and different dimensions of CRM in banking system, performance of the bank was studied in different dimensions of CRM. The findings of the study reveal that the performance of the bank is not desirable in different dimensions. Also, after investigating the difference between perceptions and clients` expectations from different factors of CRM, the result showed that from 47 
factors related to CRM in Tejarat Bank of Shiraz, there was a meaningful difference between perceptions and clients` expectations, except for 8 factors. Based on the study conducted by Sefidany et al. (2011) on the effect of internet on marketing performance of life insurance, It was indicated that using internet could increase life insurance marketing performance.

Under the title of "pure and fast strategies and marketing performance of companies "Malek Akhlaq and Rajab zadeh (2011) conducted a research study with the aim of determining the relation between provision chain strategies and marketing performance of companies producing foods and beverages in Rasht County. They concluded that two strategies of pure and fast are effective on marketing performance of producing companies.

To present a unified pattern for definition of CRM, Mehrabi et al (2009) did a research in Mellat Bank. The results showed that that changes in organizational culture, technical changes and organizational structure changes have a positive and meaningful effect on successful conducing of CRM.

\section{Theoretical Frame Work}

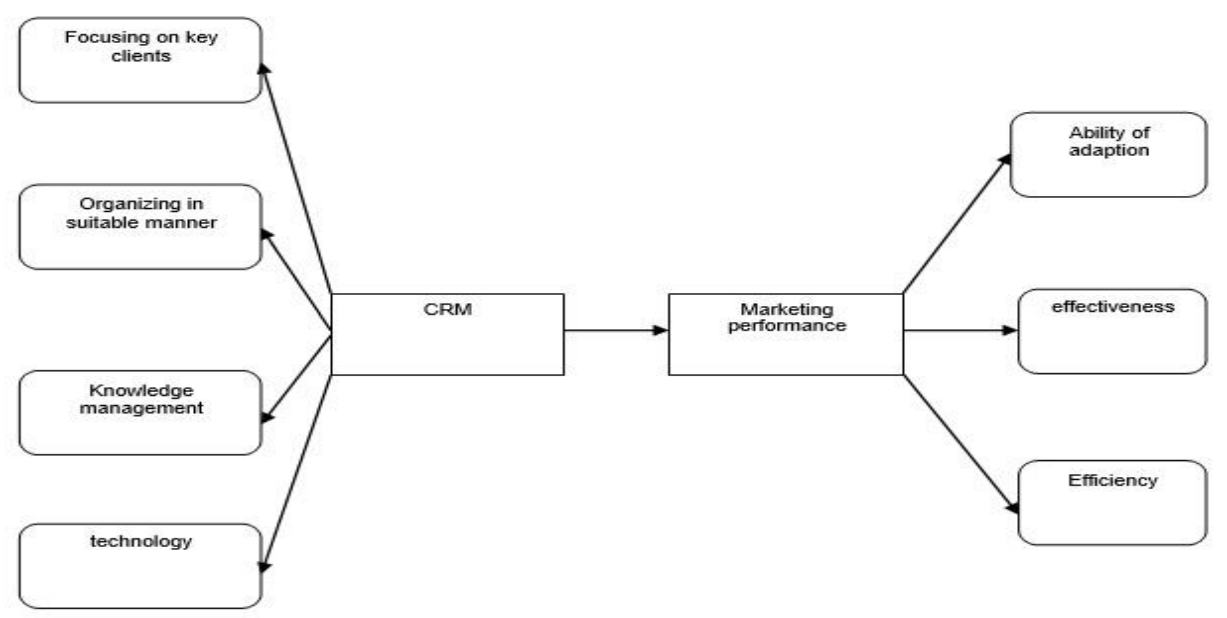

Figure 1. The relation of CRM with marketing performance
What is accounted as the key to success of modern organizations is client satisfaction. Client satisfaction is the result of material and service quality, understanding needs and trading conducts of clients. Accordingly, organizations try to improve business and organizations' marketing performance by creating a stronger relationship with clients. Bank is among organizations which needs client satisfaction to be able to survive. As a result, banks are able to improve their performance by applying CRM technique. In this research, the researcher tries to investigate effects of CRM on marketing performance of different branches in Mellat Bank of Khoram-Abad County.

The relation of CRM and marketing performance is represented in the conceptual model of the researchshown below.

According to Figure 1, CRM can improve marketing performance through key clients, CRM based on technology, knowledge management and organizing in s suitable manner. On the other hand, improving marketing performance also can lead to achieving organizational goals and as a result effectiveness, efficiency and finally adaptability of organizations can emerge. 
To achieve the research goals, the hypotheses designed are as follows:

The main hypothesis is: CRM has an effect on marketing performance. And, the secondary hypotheses are:

1. CRM has an effect on adaption performance.

2. CRM has an effect on marketing effectiveness.

3. CRM has an effect on marketing efficiency.

\section{Materials and Methods}

The research method of the current research was applied method and according to its nature which studied variables`effects, the research method was descriptive-survey.

\section{Community and sample}

Statistical community of the research for CRM was all the personnel of 5 branches in Mellat Baank of Khoram-Abad County.

According to number of total people of community which equaled to 45 , sample size was estimated 40 according to Morgan Table. Statistical community of the second variable was clients of Mellat Bank of Khoram-Abad County. In order to achieve real results and accurate calculations we had to consider size of the two communities. Therefore, client community was decided to be 45 people.

\section{Instruments}

To gather data, literature, library and internet were applied and also a standard questionnaire was used to test hypotheses. For gathering data related to CRM, a questionnaire was used containing 24 items (Hamed Bordbar, 2012). The questionnaire included 4 dimensions of key clients, organizing in a suitable manner, knowledge management and technology. Reliability and reliability of the questionnaire was approved and Cronbach Alpha was used for measuring reliability which is $0 / 852$.

A questionnaire was used containing 15 items for gathering data related to performance analysis as the second tool (Hamed Bordbar, 2012). It included effectiveness, efficiency and adaption. In both questionnaires, Likert scale was used. Cronbach Alpha of the questionnaire was 0/736.

A part of the questionnaires elicited demographic data such as age, sex, education, and organization rank and job experience.

Data Analysis

To analyze data, descriptive and inferential statistics was applied using SPSS 19.

\section{Results}

Based on the results of descriptive statistic of bank staff, 88.5 of the respondents to questionnaires were men and 11.5 were women.

Among the clients, 75 percent were men and 25 percent were women. Tables 2 and 3 represent more demographic information.

To investigate the research hypotheses, linear regression test was used.

As it is shown in Table 7, the major hypothesis of the research is rejected in confidence level of 95 percent and error level of 5 percent based on effect of CRM on marketing performance; meaning that CRM has no effect on marketing performance.

The results of the secondary hypotheses test are presented in Table 5.

Based on Table 5, it can be stated that the first secondary hypothesis is accepted, but the second and third ones are rejected. Therefore, CRM is effective in dimension of performance adaption but has no effect on effectiveness and efficiency. 
Table 2. Differentiation of staff based on demographic variables

\begin{tabular}{cccccccc}
\hline Education & percent & $\begin{array}{c}\text { Rank of } \\
\text { organization }\end{array}$ & percent & Year & percent & $\begin{array}{c}\text { Job } \\
\text { experience }\end{array}$ & percent \\
\hline $\begin{array}{c}\text { Diploma } \\
\text { Associate } \\
\text { degree }\end{array}$ & $19 / 2$ & $\begin{array}{c}\text { Employee } \\
\text { BA }\end{array}$ & $87 / 5$ & $20-30$ & 30 & $1-10$ & $57 / 5$ \\
MA & $30 / 8$ & $\begin{array}{c}\text { Expert } \\
\text { Assistant }\end{array}$ & $7 / 5$ & $30-40$ & 70 & $10-20$ & 35 \\
manager & $26 / 5$ & $40-50$ & 10 & $20-30$ & $7 / 5$ \\
\hline
\end{tabular}

Table 3. Differentiation of staff based on demographic variables

\begin{tabular}{cccc}
\hline Education & percent & Year & Percent \\
\hline Under diploma & 5 & $25-20$ & $37 / 5$ \\
Diploma & 20 & $25-30$ & 30 \\
Associate degree & 10 & $35-30$ & 15 \\
BA & $52 / 5$ & $40-45$ & 15 \\
MA & $12 / 5$ & $50-45$ & $2 / 5$ \\
\hline
\end{tabular}

Table 4. Results of regression test between CRM and marketing performance

\begin{tabular}{ccccc}
\hline $\begin{array}{c}\text { Independent variable } \\
\text { CRM }\end{array}$ & $\begin{array}{c}\text { Dependent variable } \\
\text { Marketing performance }\end{array}$ & $\begin{array}{c}\text { Sig. } \\
0 / 147\end{array}$ & $\begin{array}{c}\text { t } \\
\text { Mesult }\end{array}$ & $\begin{array}{c}\text { Res } \\
\text { Rejected }\end{array}$ \\
\hline
\end{tabular}

Table 5. Result of regression between CRM and dimensions of marketing performance

\begin{tabular}{ccccc}
\hline Independent variable & Dependent variable & Sig. & t & Result \\
\hline CRM & Adaption aspect of performance & $0 / 043$ & $2 / 147$ & Approved \\
CRM & Performance effectiveness & $0 / 766$ & $-0 / 301$ & Rejected \\
CRM & Performance efficiency & $0 / 152$ & $1 / 483$ & Rejected \\
\hline
\end{tabular}

\section{Discussion and conclusion}

The research findings show that the first hypothesis is rejected based on effect of CRM on marketing performance in 4 branches of Mellat Bank in Khoram-Abad. These results are consistent with those of Taherpour and Tayebi Pour's (2009). The results of the research indicate that the relation between marketing performance and CRM in banking industry of Iran is low. The result can be regarded as result of lack of competitiveness space between banks of Iran, where banks feel no threat in spite of losing their clients and do not follow client-orientation programs seriously.

The first secondary hypothesis was approved, proving CRM has an effect on adaption ability of marketing performance. According to the respondents, it can be suggested that in thesebranches, banks have high level of validity and confidence; however, the second and third hypotheses were ignored.

In the second and third hypotheses, CRM had effect on effectives and efficiency of marketing performance. During interviews with people, they attributed the reason for of their dissatisfaction to the lack of personnel for responding and long hours of waiting for receiving services.

Knowledge management means an organized availability of information and scientific savings so that people can use them when they are in need and to be able 
to do their daily activities with more return and in an effective way. According to above definition, one of the main reasons behind using CRM I banks of Iran is lack of knowledge management. Therefore, it is suggested that to strengthen knowledge management, CRM be applied in banks. In addition, since the most important clines in banks are key clients, it is suggested that banks raise their get awareness of the clients' expectations through launching regular surveys.

\section{References}

Abbot, J., Stone, M., Buttle, F. (2001). Customer Relationship Management in Practice-A Qualitative Study. Journal of Data Base Marketing. 9(1):24-34.

Agarwal, A., Harding. D., Schumacher., J.R. (2004). Organizing for CRM. Mckinsey Quarterly, 3: 80-91.

Amiri, E. (2009). Investigating quality of services of CRM and preparing optimum program of CRM in banking system using TOPSIS technique. Industrial management chapter in humanities faculty of Islamic Azad University. Forth year. 10:43-56.

Berry, L. (1983). Relationship Marketing. Emerging Perspectives on Services Marketing Chicago: American Marketing Association. 25-28.

Berus, A., and Ken L. (2004). Clientorientation. (Mohammed Reza Jabary, Mohammed Montazery). Tehran: Sargol Publication.

Boisvert, H. (2006). Building More Efficient Business. CMA magazine. 79(9).

Boyle, M.J. (2004). Using CRM Software Effectively. CPA Journal. 74(7):17-26.
Elahi, Sh., and Heydari, B. (2005). CRM. Tehran: Print Company and trading publication related to study institutions and business researches.

Esfandyani, M., and Dagighi ASL, A., Esmaeili Ahangar Kolaei, A. (2011). Effect of internet on marketing performance of life insurance. Insurance industry chapter. No 102. P83.

Gartner Group. (2001). CRM Economics: Figuring Out the ROI on Customer Initiative. White Paper, Stamford, CT.

Hadizadeh Moghaddam R., Mehr, H. and Haj Moghani, R. (2010). Presenting a model for applying CRM. Case study: Saderat Bank of Tehran. Articles of specialized conference of CRM.

Hoffman, T., Kashmeri. S. (2000). Coddling The Customer .Computer World. 34(50). 58-60.

Jafarnejad, A., and Shahaei, B. (2007). Organizational alacrity and fast production. Tehran: Book institute, Mehraban Nashr Publication.

Ko, E., kim, SH., Kim, M., Woo, J.Y. (2007). Organizational Characteristic and The CRM adoption process. Journal of Business research. 61: 65-74.

Malek Akhlagh, A., and Rajabzadeh, E. (2011). Pure and fast strategies and performance of company marketing. Engineering development of market magazine. No 18.

Mehrabi, J., and Babaei Ahry M., and Taati, M. (2010). Presenting a unified pattern on using definition of CRM in Mellat Bank. Development management magazine. 4: 61-71.

Peppers, D., Rogers, M., Dorf, B. (1999). Is your company ready for one-to-one 
marketing. Harvard Business Review, Boston. 77(1):151-160.

Sin, L.Y.M., Tse. A.C.B., Yim, F.H.K. (2005). CRM: conceptualization and scale development .European Journal Of Marketing. 1264-1290.
Taherpour Kalantari, H., and Tayebi Tolou, A. (2010). The relation of CRM with performance. Business management aspect. 1: 109-122.

Venous, D., and Safaeian, M. (2004). Bank services marketing. Tehran: Negah-danesh Publication.

How to cite this article: Goudarzi M., Mossallami Aghili S., Mokhtary Tajeek Z., Effect of Customer Relationship Management (CRM) on Marketing Performance, Case Study: Mellat Bank of Khorram-abad County. International Journal of Advanced Studies in Humanities and Social Science, 2019, 8(3), 301-309. http://www.ijashss.com/article_84378.html 